\title{
A report of laryngeal adenocystic carcinoma metastatic to the spleen and the role of splenectomy in the management of metastatic disease: a case report
}

\author{
Bryce W Murray*1, Lewis C Lyons², Anne T Mancino² and Sergio Huerta
}

\begin{abstract}
Introduction: Adenoid cystic carcinoma (ACC) of the larynx is a rare malignancy characterized by an indolent course and late pulmonary metastases. Metastases from the larynx to the spleen are an unusual event. In the present report, we discuss a patient with adenoid cystic carcinoma of the larynx metastatic to the spleen. A review of the literature did not yield any other such incidents. We review the clinical presentation and course of adenoid cystic carcinoma, as well as the role of splenectomy for metastases.
\end{abstract}

Case presentation: We present a case of laryngeal adenoid cystic carcinoma in a 26-year-old Caucasian man treated with total laryngectomy and ionizing radiation. He initially developed asynchronous pulmonary metastases, which were resected. Our patient subsequently presented with a symptomatic splenic lesion consistent with metastatic disease, for which he underwent laparoscopic splenectomy.

Conclusions: Splenectomy might be indicated for isolated metastases. A splenectomy effectively addresses symptoms and serves as a cytoreduction modality.

\section{Introduction}

Adenoid cystic carcinoma (ACC) is a rare, malignant tumor, which usually originates from the minor salivary glands. The laryngeal variant, arising from the glandular components of the larynx, is extremely atypical [1]. A review of the literature on ACC demonstrates only 15 cases reported in the past 40 years in a compressive analysis of the topic [2]. Another review interrogated 1342 cases of laryngeal tumors and identified five cases of ACC [3]. The management for both the laryngeal and glandular components consists of surgical resection and ionizing radiation, which is aimed to achieve local control. However, these modalities do not seem to affect mortality, which is typically the result of metastatic disease [2,4]. Prophylactic lymph node dissection is only indicated for clinically involved nodes $[5,6]$. ACC is characterized by an indolent growth pattern and late distant metastasis,

* Correspondence: brycew.murray@va.gov

1 Dallas VA Medical Center, Surgical Services (112), 4500 S Lancaster Road, Dallas, TX 75216, USA

Full list of author information is available at the end of the article most commonly to the lungs [2]. Owing to the slow growth and indolent nature of this malignancy, survival for patients with laryngeal ACC is measured in decades $[2,5]$. Thus, in contrast to other malignancies, ACC survival is typically not measured as five-year mortality, but more commonly at 10 or 20 years [7]. Pulmonary metastasectomies have been reported for isolated lesions from ACC [8]. Glandular ACC has a predilection for the lungs, but has also been reported to metastasize to other organs including brain, bone, liver, thyroid and spleen [9]. The natural history of salivary gland ACC indicates that average time between diagnosis of the primary tumor and death was 60.1 months and the interval between occurrence of metastases and death was 33.0 months [9].

In the present discussion, we address the need to perform a splenectomy in an unusual clinical situation of a metastatic lesion from ACC. We present a review of the literature on metastatic lesions to the spleen and the role of splenectomy for their management. 


\section{Case presentation}

A 26-year-old Caucasian man was referred to the surgical service with an enlarging splenic mass and left upper quadrant pain. The pain was described as dull with no exacerbating factors. He had no nausea or vomiting and no other systemic complaints. He had a history of laryngeal ACC that was treated with total laryngectomy and adjuvant radiation three years prior to this clinical visit. Within a year of the original diagnosis and treatment of ACC, our patient developed a single right lung metastasis for which he underwent thoracotomy with resection. This was followed by recurrence in the ipsilateral lung, which was again resected. He was started on Tarceva (erlotinib), an EGFR inhibitor used to treat non-small cell lung cancer, but the therapy was discontinued secondary to an intolerable rash.

During follow up a computed tomography (CT) scan of the chest demonstrated bilateral lung nodules, which were consistent with metastatic disease (Figure 1B). However, there were no symptoms attributable to these lesions. The CT scan also demonstrated a lesion in the spleen that measured $4 \mathrm{~cm}$ and was approximately $1 \mathrm{~mm}$ from the splenic capsule (Figure 1A). He was referred to the surgical service when a follow up CT scan of the abdomen three months later demonstrated progression in size of the lesion by $1 \mathrm{~cm}$ and our patient complained of left upper quadrant abdominal discomfort. There was no evidence of other intra-abdominal disease. Due to the progression in size of the splenic lesion, its proximity to the capsule with potential complications of rupture or local advancement, and in light of our patient's symptoms the decision was made to proceed with laparoscopic splenectomy. He was given appropriate pre-operative immunization. At the time of surgery, there was no evidence of other intra-abdominal disease. The spleen (Figure 2A) was removed intact through an enlarged port site incision. Pathologic examination (Figure 2B) showed a $5.2 \times$ $4.3 \times 4 \mathrm{~cm}$ single metastatic nodule within $0.1 \mathrm{~cm}$ from the capsule. The mass shows mucoid areas in the center and microscopically had features characteristic of adenoid cystic carcinoma with a predominant cribriform growth
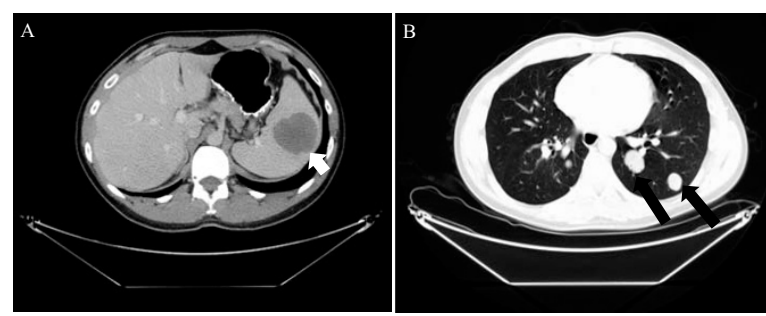

Figure 1 Computed tomography revealed splenic lesion ( $A$, identified with arrow) and demonstrating metastatic lung lesions (B, identified with arrows).

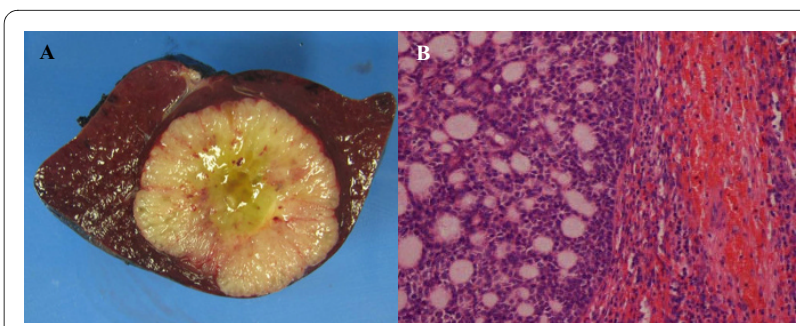

Figure 2 Gross pathologic specimen (A), and microscopic view demonstrating characteristic cribriform pattern abutting splenic capsule (B).

pattern. He had a routine convalescence, and is currently alive and well.

\section{Discussion}

Involvement of the spleen as a result of metastatic disease is an unusual event, which occurs in $0.96 \%$ to $7.1 \%$ of patients with carcinoma as demonstrated by autopsy examinations [10,11]. Splenic metastases often herald late stage disease and are typically associated with multi-visceral metastatic disease. The organ of origin is most commonly breast, followed by lung, colorectal, ovary, stomach and skin (Figure 3) [12]. Isolated splenic metastasis is an even more atypical condition. A recent review of the literature reported only 93 cases of solitary splenic metastasis [13]. The majority of metastases were of colorectal and ovarian origin (Figure 4) [13]. The increased incidence of ovarian splenic metastases may be related to the route of spread (peritoneal seeding versus blood borne metastases) and the close radiographic and clinical follow-up that these patients undergo.

Splenectomy for metastases has been previously reported (Table 1). The most common indication for splenectomy is as part of cytoreductive therapy in patients with ovarian cancer as this might increase the therapeutic efficacy of systemic chemotherapy [14-16]. A splenectomy for the management of colon cancer and melanoma has also been successfully performed as a dis-

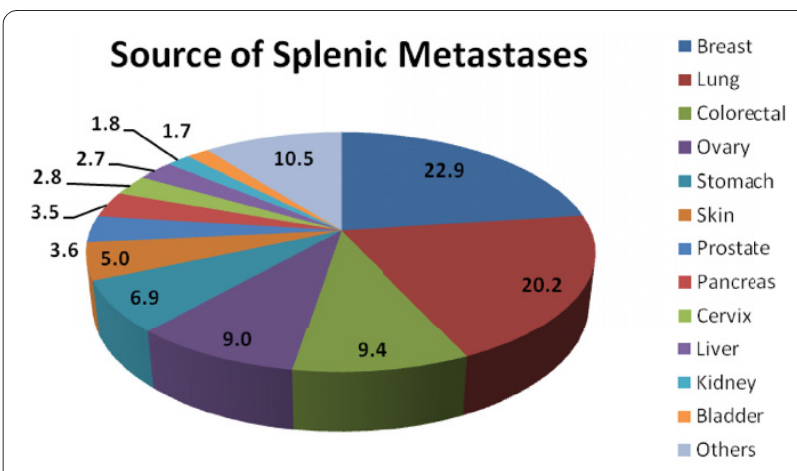

Figure 3 Chart showing the source of splenic metastases from a large autopsy review[12] 


\section{Source of Isolated Splenic Metastasis

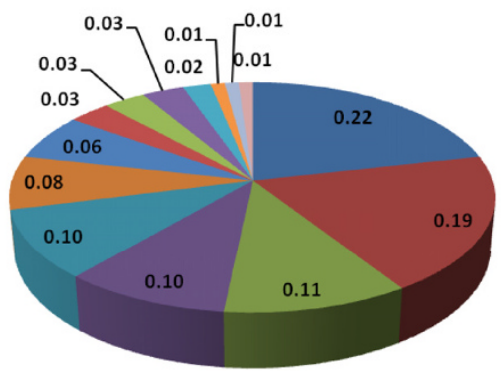 \\ - Colorectal \\ avary \\ I Lung \\ - Endometrium \\ Eidney \\ astomach \\ nervix \\ Breast \\ - Prostate \\ -Esophagus \\ Melanoma \\ a Fallopian tube \\ w Thyroid \\ =Unknown}

Figure $\mathbf{4}$ Chart demonstrating source of solitary splenic metasta$\operatorname{sis}[13]$.

ease control strategy in the management of these malignancies $[17,18]$. The cases presented in Table 1 indicate the potential therapeutic benefit of splenectomy as the average post-operative survival for these patients is from 11.1 to 29.3 months.

The present report is unique in its presentation of laryngeal ACC metastatic to the spleen. This case also illustrates the need to proceed with splenectomy for the management of symptoms and also to prevent substantial adverse outcomes that might result from further tumor involvement. Because of the indolent nature of ACC, a splenic lesion might achieve substantial growth, which if left untreated might rupture causing lethal hemorrhage or erode into the adjacent structures (i.e. diaphragm) causing significant symptoms and morbidity.

\section{Conclusions}

Splenic metastasis is a rare event. When it occurs, splenic metastasis is usually associated with widespread metastatic disease. Splenectomy may be considered for patients with isolated disease, patients needing cytoreduction prior to adjuvant therapy, and for those patients with symptomatic disease.

\section{Consent}

Written informed consent was obtained from the patient for publication of this case report and any accompanying images. A copy of the written consent is available for review by the Editor-in-Chief of this journal.

\section{Competing interests}

The authors declare that they have no competing interests.

\section{Authors' contributions}

BM was involved in patient evaluation and management. He is the primary author. TL was involved in patient data collection. AM was the supervising surgeon for the case and was involved with editing the article. SH was involved in editing the article. All authors read and approved the final manuscript.

\section{Author Details}

1Dallas VA Medical Center, Surgical Services (112), 4500 S Lancaster Road, Dallas, TX 75216, USA and 2University of Arkansas for Medical Sciences, 4301 W Markham, Little Rock, AR 72205, USA

Received: 24 October 2009 Accepted: 6 July 2010

Published: 6 July 2010

Table 1: Splenectomy for metastatic disease.

\begin{tabular}{|c|c|c|c|c|c|c|}
\hline Reference & de wilt [17] & Lee [15] & Nicklin [16] & Gemignani [14] & Sileri [18] & Agha-Mohammadi [19] \\
\hline Number & 15 & 31 & 18 & 6 & 16 & 54 \\
\hline Age & $52.7(37-84)$ & $61(39-79)$ & $58.1(30-78)$ & $59(58-60)$ & $65(33-81)$ & $\mathrm{n} / \mathrm{a}$ \\
\hline M:f & $6.5: 1$ & 01:09.3 & $0: 18$ & $0: 06$ & $1.8: 1$ & $\mathrm{n} / \mathrm{a}$ \\
\hline \multicolumn{7}{|l|}{ Primary tumor } \\
\hline Gynecologic & 0 & 23 & 14 & 6 & 0 & 33 \\
\hline Colorectal & 0 & 2 & 0 & 0 & 16 & 8 \\
\hline Melanoma & 15 & 0 & 0 & 0 & 0 & 1 \\
\hline Lung & 0 & 1 & 0 & 0 & 0 & 5 \\
\hline Peritoneum & & 1 & 3 & 0 & 0 & 0 \\
\hline Solitary lesion & $6 / 15$ & $\mathrm{n} / \mathrm{a}$ & $\mathrm{n} / \mathrm{a}$ & $\mathrm{n} / \mathrm{a}$ & $16 / 16$ & $\mathrm{n} / \mathrm{a}$ \\
\hline \multirow{4}{*}{$\begin{array}{l}\text { Survival in months } \\
\text { (range) }\end{array}$} & $11.3(1-31)$ & $22.9(1-72)$ & 11 dead @ 12 (5-59.5) & NED @ 28 (6-65) & not reported & 31 NED @ 29.1 (6-144) \\
\hline & & & 5 alive with disease & & & 5 with disease @ 20.2 (6-72) \\
\hline & & & 2 NED & & & 6 dead \\
\hline & & & & & & 12 unknown \\
\hline
\end{tabular}




\section{References}

1. Tewfik TL, Novick WH, Schipper HM: Adenoid cystic carcinoma of the larynx. J Otolaryngol 1983, 12:151-154.

2. Moukarbel RV, Goldstein DP, O'Sullivan B, Gullane PJ, Brown DH, Wang L, et al:: Adenoid cystic carcinoma of the larynx: a 40-year experience. Head Neck 2008, 30:919-924.

3. Eschwege F, Cachin Y, Micheau C: Treatment of adenocarcinomas of the larynx. Can J Otolaryngol 1975, 4:290-292.

4. Chen AM, Bucci MK, Weinberg V, Garcia J, Quivey JM, Schechter NR, et al: Adenoid cystic carcinoma of the head and neck treated by surgery with or without postoperative radiation therapy: prognostic features of recurrence. Int J Radiat Oncol Biol Phys 2006, 66:152-159.

5. Conley J, Dingman DL: Adenoid cystic carcinoma in the head and neck (cylindroma). Arch Otolaryngol 1974, 100:81-90.

6. Ferlito A, Caruso G: Biological behaviour of laryngeal adenoid cystic carcinoma. Therapeutic considerations. ORL J Otorhinolaryngol Relat Spec 1983, 45:245-256.

7. Donovan DT, Conley J: Adenoid cystic carcinoma of the subglottic region. Ann Otol Rhinol Laryngol 1983, 92:491-495.

8. Bobbio A, Copelli C, Ampollini L, Bianchi B, Carbognani P, Bettati S, et al: Lung metastasis resection of adenoid cystic carcinoma of salivary glands. Eur J Cardiothorac Surg 2008, 33:790-793.

9. van der Wal JE, Becking AG, Snow GB, van der Waal I: Distant metastases of adenoid cystic carcinoma of the salivary glands and the value of diagnostic examinations during follow-up. Head Neck 2002, 24:779-783.

10. Berge T: Splenic metastases. Frequencies and patterns. Acta Pathol Microbiol Scand A 1974, 82:499-506.

11. Sauer J, Sobolewski K, Dommisch K: Splenic metastases--not a frequent problem, but an underestimate location of metastases: epidemiology and course. J Cancer Res Clin Oncol 2009, 135:667-671.

12. Lam KY, Tang V: Metastatic tumors to the spleen: a 25-year clinicopathologic study. Arch Pathol Lab Med 2000, 124:526-530.

13. Comperat E, Bardier-Dupas A, Camparo P, Capron F, Charlotte F: Splenic metastases: clinicopathologic presentation, differential diagnosis, and pathogenesis. Arch Pathol Lab Med 2007, 131:965-969.

14. Gemignani ML, Chi DS, Gurin CC, Curtin JP, Barakat RR: Splenectomy in recurrent epithelial ovarian cancer. Gynecol Oncol 1999, 72:407-410.

15. Lee SS, Morgenstern L, Phillips EH, Hiatt JR, Margulies DR: Splenectomy for splenic metastases: a changing clinical spectrum. Am Surg 2000, 66:837-840

16. Nicklin JL, Copeland LJ, O'Toole RV, Lewandowski GS, Vaccarello L, Havenar LP: Splenectomy as part of cytoreductive surgery for ovarian carcinoma. Gynecol Oncol 1995, 58:244-247.

17. de Wilt JH, McCarthy WH, Thompson JF: Surgical treatment of splenic metastases in patients with melanoma. J Am Coll Surg 2003, 197:38-43.

18. Sileri P, D'Ugo S, Benavoli D, Stolfi VM, Palmieri G, Mele A, et al.:

Metachronous splenic metastasis from colonic carcinoma five years after surgery: a case report and literature review. South Med J 2009, 102:733-735.

19. Agha-Mohammadi S, Calne RY: Solitary splenic metastasis: case report and review of the literature. Am J Clin Oncol 2001, 24:306-310. noma metastatic to the spleen and the role of splenectomy in the management of metastatic disease: a case report Journal of Medical Case Reports 2010, 4:207

\section{Submit your next manuscript to BioMed Central} and take full advantage of:

- Convenient online submission

- Thorough peer review

- No space constraints or color figure charges

- Immediate publication on acceptance

- Inclusion in PubMed, CAS, Scopus and Google Scholar

- Research which is freely available for redistribution

Submit your manuscript at www.biomedcentral.com/submit
C Biomed Central 